\title{
ALFONSO REYES. IN MEMORIAM
}

A principios de $1930 \mathrm{mi}$ hermano Carletto, de regreso a Milán tras larga gira en Sudamérica, nos describió la recia vida intelectual de Buenos Aires; nos habló con entusiasmo del primer mexicano que había conocido en su vida, el embajador de México. Se llamaba Alfonso Reyes. Tenía un interés especial por la danza expresionista de Carletto y lo invitó varias veces a las reuniones que organizaba en la embajada. En sus intervenciones brillaba su excepcional cultura humanista; conquistaba a todos con su sabiduría traducida en generosos exabruptos. Carletto tuvo la clara sensación de que Alfonso Reyes se había vuelto el centro de la intelligentsia porteña.

Dos años más tarde, nuevo encuentro en Río de Janeiro, donde Reyes, ahora embajador en Brasil, se había rodeado otra vez con lo mejor de la gente pensante y, desde luego, productiva en su propio campo: escritores, artistas plásticos, músicos. Desde entonces se remonta su amistad con Cándido Portinari y Heitor VillaLobos. Alfonso Reyes se había vuelto el gran señor del movimiento intelectual carioca. En las reuniones de la embajada, cuya buena hada era la encantadora doña Manuela, Carletto, el futuro coreógrafo de La Scala, era tal vez el contertulio más joven.

Reyes, lingüista de excepción, desde luego latinista e italianista (y que en sus años mozos en París escribió con "verve" gala versos franceses), amó y dominó el portugués; una de las razones por las cuales conquistó tanta simpatía por México es que la lengua "oficial" de las reuniones era la del país, no menos hispánica de la que hablamos. En su prosa castellana postbrasileña encontramos una palabra hermosa e intraducible: saudade, cuya hondura y ternura le da derecho de ciudadanía en español. También Carletto dominó el portugués, lengua que, espontáneamente, usó al llegar a la frontera de México en 1950; pocas semanas más tar- 
de se expresaba en un guirigay italofrancoluso ya sazonado con palabras de aquí. ¿Tengo que recordar que escribió en castellano dos novelas que Joaquín Mortiz publica en segunda edición: Lady Iguana y Los tatarabuelos?

Yo llegué a México en 1940, pocos meses después del regreso de Reyes a su patria. Lo visité con timidez porque estaba muy consciente de mi insignificancia literaria. Mi poesía se limitaba a un libérculo que llamé Versos decaglotos, o sea en diez idiomas, en que no faltaba un soneto portugués escrito después de dos lecturas de $O_{s}$ Lusiadas, titulado Temixtitão. Perfecta mediocridad. Poesía, incluso con personajes mitológicos, es la que escribí a los 13-14 años; en prosa había publicado, a los 14 años, un estudio sobre el luganés Monte Bré, patria de maestros comacinos de nuestros días, como el ahora ultranonagenario pintor Luis Taddei. El único mérito que tenía al visitar a Alfonso Reyes era ser el hermano de Carletto. Me recibió con cortesía; me hizo visitar los dos pisos de la imponente biblioteca que su ilustre amigo de Madrid en 1920, Enrique Díez-Canedo, bautizaría Capilla Alfonsina. Aquí el capellán Alfonso seguía entregado a sus estudios, máxime a los helenísticos.

Uno de sus más sabios y devotos discípulos, José Luis Martínez (ahora presidente de la Academia Mexicana de la Lengua como lo fue, entre 1957 y 1959, su maestro), recopiló la correspondencia de Reyes con Pedro Henríquez Ureña entre 1907 y 1914. Pedro, joven antillano que al iniciar su carteo tenía 22 años y una sólida formación literaria adquirida en Santo Domingo y Nueva York, escribía a Alfonso, cinco años menor pero dotado de una luminosa inteligencia creativa, cartas que obligaban a Reyes a medirse con Henríquez Ureña en los arduos y sutiles ejercicios de gimnasia mental. Las 500 páginas del epistolario son de grata lectura para mí en particular. Nombres, nombres, nombres, para mí recuerdos de mi juventud europea. He aquí a Marinetti, fundador del futurismo, que frecuentaba mi casa de Milán, acompañado por sus talentosos secuaces, entre ellos los pintores Carrá, Severini y el malogrado Boccioni. Luisa Tetrazzini, que conocí en Lugano con su elegante chofer uniformado, discreto y devoto amante de la diva. Tina di Lorenzo, que vi actuar, como a Eleonora Duse y a los dos Ermetes, Novelli y Zacconi. Hermann Sudermann, con quien correspondía mi padre; Marcel Proust, con cuya hermana tuve gratas conversaciones en París acerca del gran buscador del tiempo perdido; el dramaturgo Roberto Braceo, amigo de mi padre como Guido da Verona, el autor de Mimi Bluette, 
que impulsó a Reyes a perfeccionar su italiano; Jules Romains, Gabriele d'Annunzio, Ada Negri, Arthur Rubinstein; Romain Rolland, que nos visitó en compañía de su padre y su hermana: Premio Nobel afable y modesto. En Murnau viví un mes en casa de Kandinsky; en Munich iba todas las noches a escuchar, en su casa, a Paul Klee, excelente violinista. ¡Cuántos nombres más del carteo podría añadir!

Volvamos a Reyes. Me hizo sonreír una observación acerca de su padre. Dice: "A mi papá, por la edad y el trabajo, [.. . ] lo invaden ciertas debilidades seniles"'. El general Bernardo Reyes tenía entonces 59 años. Cinco después, la tragedia: el general cae acribillado frente al Palacio Nacional. El trauma que Alfonso sufre durará toda la vida. Cambiar de aire se vuelve una necesidad. Se embarca a París donde será, durante un año, segundo secretario de la Legación de México. Tenía 24 años. Intensa correspondencia con Henríquez Ureña. Los acontecimientos de México tienen su repercusión en París: Venustiano Carranza, presidente de la República el 20 de agosto de 1914, días después despide a todo el personal de la Legación. El 2 de septiembre Reyes sale en tren diplomático a Burdeos y alcanza San Sebastián. Escribe al amigo Pedro: "He saboreado la delicia de no tener libros ni necesitar de ellos para pensar. Si logro escribir sin ellos, habré conquistado mi salvación, seré plenamente fuerte. Los bienes materiales nos secan, nos corrompen"'2.

Días después Alfonso Reyes llegará a Madrid. El segundo tomo del epistolario (1915-1946, año de la muerte de Pedro), que José Luis Martínez cuidará con amor, como el primero, tiene que salir y saldrá; ojalá sea pronto. Afortunadamente poseo un libro, titulado Cortesía, que Reyes publicó en corta edición para sus amigos, en 19483: Cortesía en el sentido de regalo. Lo considero un gran regalo, aún más precioso por su dedicatoria. No sólo me hace revivir el treintenio de la presencia física del maestro en México, sino que también contiene una abundancia de nombres -o sea de personajes - como en el carteo con Henríquez Ureña. Nombres, nombres, nombres, de mexicanos y refugiados españoles que conocí aquí entre 1940 y (casi) 1990. Todos ya descansan en la eternidad, menos dos: uno es Dámaso Alonso; el otro, el único que no he tenido la suerte de encontrar en Roma o en España:

1 Alfonso Reyes-Pedro Henríquez Ureña, Correspondencia 1907-1914, ed. J. L. Martínez, FCE, México, 1986, p. 66.

${ }^{2}$ Ibid, p. 478.

${ }^{3}$ Las Cortesias de Reyes están reunidas en $A R O C$, t. 10. 
el poeta Rafael Alberti, al que admiro férvidamente.

Encuentros de Reyes en Madrid, que se reiteran en México: Enrique Díez-Canedo, poeta, traductor y crítico literario, amigo muy cercano de Alfonso; Adolfo Salazar, musicógrafo, compositor y escritor. Mi propósito es evocar aquí a los amigos de Reyes que fueron también los míos. En primer lugar el ilustre internacionalista Isidro Fabela, a quien debo el cambio radical de mi vida. Yo producía en Suiza algo para escribir (¡tenía que ser!), algo que yo creé: la máquina más menuda y más ligera del mundo. En Ginebra Fabela me convenció que abandonara mi devoción a Santa Tecla, que me estableciera en México y me volviera hombre de estudio, porque tal era mi vocación. En sus últimos años don Isidro fue mi vecino en Cuernavaca y nos veíamos con frecuencia.

¿Quién sigue? Un banquero y poeta, Eduardo Villaseñor, con quien hice un aventuroso vuelo de México a Nueva York en 1937, interrumpido por la niebla en Waco, Tejas, y reanudado en Fort Worth al cabo de largo viaje nocturno en auto, a vuelta de rueda. En 1938 volví a verlo en París. ¿Quién más? El poeta yucateco Antonio Mediz Bolio, autor de La tierra del faisán y del venado, perfecto bilingüe maya-español. Martín Luis Guzmán, uno de los mejores prosistas en castellano de este siglo, mexicanista a ultranza, lo que no le impidió dirigir dos diarios en Madrid. Manuel M. Ponce, el compositor cuyas obras para guitarra dio a conocer Segovia en todo el mundo. Lo conocí en Aguascalientes en 1943; cierta vez fuimos a Huichapan para asistir a la colocación de una placa de mármol en la casa del músico Abundio Martínez. El pintor Ángel Zárraga y su hermano, el arquitecto Guillermo; otro pintor, éste, famoso: Diego Rivera; otro más, Roberto Montenegro, que me pintó en los cincuentas; el paisajista, volcanista e incomparable mitómano Doctor Atl, a quien visité dos veces mientras pintaba el Paricutín. Miguel Ángel Asturias, el novelista guatemalteco Premio Nobel; Salomón de la Selva, helenista y mitólogo nicaragüense, autor de Ilustre familia; el poeta papanteco José Núñez y Domínguez, embajador en la Dominicana, con quien visité una de las tumbas de Colón; Alfonso Teja Zabre, novelista e historiador, embajador en Honduras, que organizó una conferencia mía sobre Morazán en el mejor teatro de Tegucigalpa; dos de los Siete Sabios, Antonio Castro Leal, que me recibió con afecto en París cuando era embajador de México en la UNESCO, y Alfonso Caso, que me invitó a ver con él el Tlalocan de Tepantitla, días después del descubrimiento; Caso aprobó mis investigacio- 
nes en el ámbito del México antiguo, con ánimo fraternal. ¿Otros amigos de Reyes y míos? Dos poetas que merecen el epíteto de grandes: Enrique González Martínez y Carlos Pellicer. Con Carlos conocí las ruinas olmecas de La Venta años antes de su traslado a Villahermosa. El doctor Luis Lara Pardo, autor de un diccionario biográfico mexicano publicado todavía en París; el poeta tlaxcalteca Miguel N. Lira; el lingüista asturiano Ricardo de Alcázar, Florisel (ambos seudónimos), quien durante las meriendas en la Flor de México me impartía excelentes clases de estilo.

Hay un detalle en el libro Cortesía que me concierne directamente: su epígrafe. Dice:

Moró mucho en Lombardía para aprender cortesía.

Razón de amor (siglo XIII)

Yo nací en Lombardía, viví veinte años en Lombardía; pero en el caso de Alfonso Reyes, el más insigne hombre de letras que ha producido México en este siglo, es él quien le dio a Carletto en Buenos Aires y en Río, y a mí en México, cátedra de cortesía. Apreció mis investigaciones en varios campos del saber durante un treintenio, cuando otros las ignoraban; me alentó y me estimuló. Dos ejemplos: me llamó "deleitoso e incansable buzo"; mis busquedas alfabetológicas con la solución de añejos problemas (dos libros publicados por la Academia Mexicana de Ciencias), le interesaron al punto de escribirme: "Navego entre sus páginas como en un mar de delicias".

Años después de su partida, su nieta Alicia me ofreció grata hospitalidad en la Capilla Alfonsina que tan acertadamente dirige, para que yo diera a conocer mi interpretación del escudo nacional a la luz de pensamiento prehispánico.

En el centenario del nacimiento del poeta, del erudito, del helenista autor de Ifigenia cruel, del genial prosista de Visión de Anáhuac, del inolvidable amigo, me uno emocionado a los que reconocen la grandeza del humanista integral que fue Alfonso Reyes. 